\title{
Wesley Hagan, location manager
}

Wesley Hagan has worked as a location manager for number of Hollywood studios over his twenty-year career, most recently on the feature films Hidden Figures (2016) and Selma (2014). In this conversation, Hagan breaks down the responsibilities of a location manager, the shift in productions from Hollywood to Atlanta, and the increasing importance of location managers in a mobile production environment.

\section{What does a location manager do?}

Location managers are one of the first people to see a script. We work very closely with the production designer in both film and television. Producers are also key collaborators in television. In features, it's the director.

Location managers break down a script into different locations based on what the narrative requires, and then we start thinking about what's realistically possible. Do we find it or build it on a stage? It's a little more complicated with features because you're likely to cover a more expansive geography. In those instances, I'm the first person on the ground to see if it's even possible to shoot where they might want to shoot. I could end up anywhere in the United States; rebates are driving that process now. It has really narrowed the options.

Early in the process we have lots of creative discussions with our collaborators. We need to know how the key players are envisioning the look of the series or feature. I start picking locations, lots and lots of locations, based on those conversations. Options are absolutely necessary when you're trying to mesh your creative vision with that of the producer or director and production designer. Oftentimes 
I'm working with the production designer on a feature before the director is even hired. I provide him or her with thousands and thousands of photos, which they help to narrow down so we can present a short list to the director. It's a process of weeding out what does and doesn't work until we finally have a manageable list from which we can start choosing final locations.

It is at this point where the creative process really needs to consider logistical concerns. It's always schedule driven, of course. We want a location, but is it available when we need it? We have to consider the weather at the time of year we're scheduled to film. Is it going to be winter when we need it to be spring? When are the actors available? It's an intense, detail-oriented process of collaboration and negotiation - the goal is to strike the perfect balance between creative vision and logistical realities.

Once we get a schedule tentatively finalized, we have a tech scout with the department heads to make sure the locations work for their needs. They'll tell me things like, "I want to mount a light on that corner of the building. It's a night shot, and I want an interior light on in that particular window of this skyscraper and this window in that skyscraper but all other windows dark. I want a car to come speeding around the corner to crash into another car in front of this building." We also need to make sure the location is accessible and safe. Can we access the location with our lighting rigs? Can we find spaces to park our trucks? Where are we going to house the extras? Are there overhead electrical wires that will get in the way? I keep track of it all to make sure we can do it-that's where permits, contracts, and permissions come into play.

In television, this whole process happens in a matter of weeks. Sometimes a producer will hand you a script and say, "We need this tomorrow!" You have to be on your toes and have an idea of what's available at a moment's notice. In features, we have three to six months to prep. So, time pressures are a big difference between the two.

I start to put together my department once I have my list of locations. This is when you start making deals with private homeowners, business merchants, and municipal or state authorities. It's an arduous task that requires a great deal of support, especially for features. They have become so massive, and we're no longer making them in our own backyard [Los Angeles]. You can't handle them without a really solid team behind you. You need people who have done it before, who can think on their feet, and who can think three steps ahead to preempt any potential problems. It's absolutely critical for me because I'm only as good as the people I hire.

\section{Can you sketch out the department for us?}

It depends on the size of the project, but typically the location department will have a location manager and a couple of key assistant location managers. On larger 
shows you'll have a supervising location manager. You'll then find two location managers and each will have a key assistant if the show warrants it. These positions are all filled by seasoned veterans. Additionally you'll have assistant location managers. This is an entry-level position. Their duties include, but are not limited to, helping with crowd control during filming. They'll take care of the dog barking in the background. They'll help secure signatures from residents for their approval to film in their neighborhoods.

In Los Angeles, the union [Local 399] keeps the department's job categories distinct with a very clear process for advancement. You have to work so many days as an assistant before you can become a key assistant and then so many days as a key assistant before you can become a location manager. Likewise, if you're a location manager but want to take a job as a key assistant because you can't find work, then you can't accept another location manager job for a whole year. You're committing to your decision to step down a rank. It's a very smart process. It forces you to think about your career and guarantees a certain skill level as you advance professionally.

That's not the case in Atlanta, where there is a different local [Local 728] that doesn't have the same rules governing job distinctions and advancement. You can go from being a production assistant on one feature to a location manager on the next. Location managers are highly dependent on their assistants' skills and experience. Without a strong team, you run the risk of pitfalls that could have been avoided during prep.

Sometimes people are smart enough to figure it out and build a successful career. But more often it just confuses a process that was designed to help us develop our craft in a logical, linear fashion.

So it's the wild, wild East?

I wouldn't describe it that way. It is just so busy here that the supply doesn't meet the demand. We're pulling people from everywhere just to keep up with the work. They will hire someone as a manager who has only been an assistant and then two weeks later that person makes a mistake. Then they'll realize, “Okay, we need to call somebody else in who is qualified."

We've read that staffing is a major issue in Georgia, with one out of every two productions suffering shortages, and that the location department is one of the weakest in the region.

Managing locations involves so much work. It's not only a creative process but also a logistical one. It's so demanding to preserve a creative vision while you're balancing logistics, scheduling, and a budget. I'm responsible for anything from 
$\$ 1$ to $\$ 2$ million on the type of features I do. There are so many different facets to the job that you can't just "step into it" without some training. They're hungry for location managers in Atlanta right now because the field is so thin. I was fortunate enough to have the experience in Los Angeles. You can throw me into the mix in any city, and I'll figure it out. But, again, it is paramount that I surround myself with the right people.

The "right people" assumes some knowledge of the actual location. You have to surround yourself with people who can help you navigate a terrain with which you are less familiar.

Correct. I understand how to creatively put the project together. I understand how to manage the department. I understand how to budget the department. I understand how to negotiate logistics and schedules. But I may not know the region's geography. But it doesn't take long for a good location manager to figure it out. Once you've done two or three projects in an area, you get comfortable. But I still hire one or two local location scouts who know their way around the city really well.

So you've got your team together and you start negotiating with local residents and businesses. Now you focus on permissions?

Once we've finished the tech scout, it becomes a contract and permit issue. If we're filming in a corporate office building, we need a contract with them to ensure they will let us do the stuff we need to do, like keeping the lights on overnight. We also negotiate payment. Then we approach the city to propose what we want to do. It helps to say we have permission from the building; now we're asking permission from you. We also need the city's help to ensure we get the proper permits to close streets and reroute traffic. We work with the roads and transportation departments and the police department. I'll often hire an independent security officer who has their own team of security professionals, and we discuss our road plans, street closures, sidewalk closures, and so on. We have to close down most of the surrounding area for safety reasons. We need to be able to control the environment we're filming in, and that's often a difficult task once you leave the soundstage. People live and work in these areas! Having that security expertise is helpful when we submit our plans to the city for approval.

This is a very extensive, lengthy process. Contracts often get held up because of negotiations over money, sometimes liability. Permits always are about liability. The city wants to make sure we're safe, and we're not causing unnecessary disruption to traffic, residents, and local businesses. If residents or merchants are unhappy, the city will hear about it, and that makes our jobs that much more difficult. I was on a film once that needed to shut down Hollywood Boulevard 
for a length of time. I had to speak with every single merchant on that street, and make individual deals based on what it was we were doing that affected that particular business. Maybe we just needed people walking in and out of the store while we filmed in front of it. Maybe we needed to dress the windows to make it look like a different business. All of these contingencies affect your negotiation, and the price. It requires a particular skill: you have to be able to communicate with everyone. You meet all kinds of people who have all kinds of different perceptions of what we are and what we want, and a lot of people think that the movie companies are an endless bank account that can just hand out money, which is not necessarily the case. I have limited funds.

But I love it. It's always different. I've seen places nobody else gets to see. I think I've been on the rooftop of most every building in downtown Los Angeles and Atlanta. I meet so many interesting people, residents and business owners. I have to talk to them. I learn about their lives. It's a fascinating education.

I've had to negotiate with gangs before. I was the location manager on a Danny Cannon and Jerry Bruckheimer production a few years ago-a cop show for Warner Bros. We were filming a gunfight scene in East L.A. Of course we picked one of the toughest, grittiest neighborhoods in the area. Gunfire is something you hear there on a regular basis. But we still had to knock on doors. We still had to talk to everybody. You need those permissions and signatures no matter where you shoot. Yet, in those neighborhoods, they're even more reluctant to speak with you. Yards are fenced with dogs ready to bite you if you pass the gate! I ended up hiring a guy who worked with the gangs. He was well known in the neighborhood and was instrumental in making it okay for us to be there. He would let me know, “That house there? You'll need to pay them \$1,000." Absolutely, whatever you say. He made sure the residents knew we were just making a movie, which helped prevent us from having our equipment stolen or our trucks tagged. In those cases, it's worth every penny to have someone like that help you navigate. Otherwise you end up spending more to solve much bigger problems.

Right now I'm filming The Accountant (2016) in Atlanta. I'm in an entirely different neighborhood, similar to Bel Air or Hancock Park [in Los Angeles]. Yet we just spent three nights in a row from six at night to seven in the morning shooting .50 caliber and automatic weapons. I start with the city, explaining what we hope to accomplish. They'll nod their heads at me and say, "Well, we need to talk more about this." You better start that conversation well in advance of when you need to film those scenes because you can expect a number of follow-up meetings with the city, the police, and neighborhood organizations. We start posting flyers all over the neighborhood. We write letters to each of the residents with as much information as possible: who we are, what we're doing, when we're doing it, and for how long. Cities require signatures from 90 to 100 percent of the residents in areas being affected by filming. In this case, Atlanta wanted a signature from every single resident within 
a 250-square-foot radius from the house where the filming was happening. My assistants were working around the clock just to catch people at home.

\section{What happens when the cameras start to roll?}

Once filming starts, you're on a nonstop, high-speed train with the potential for all hell to break loose. Your job is to keep that train on track. Ideas are constantly changing or evolving. A director will say, "I was thinking last night. I know we talked about this location for the last three months, but now I have a new idea!" You're up at two in the morning to set up base camp. You are there to make sure crew can park and find the shuttle to the location. You are there to make sure craft services are ready to go. Do they have a space to set up? I'm in charge of everyone's comfort. Do they have a place to eat? Do they have shelter in case it rains? Do they need heat or air conditioning? Did the port-a-potties arrive? You're praying that everything you've prepped and planned for over the past four months proceeds accordingly.

Are you an on-set problem solver?

Locations are the first to arrive and last to leave. Morning is the most crucial part of the day. If I've done my job well, the crew will get its first shot off with no incidents related to the location. I'll leave that location six or eight hours later in the hands of a key assistant to resolve problems and ensure it's properly shut down at the end of the day. It's time for me to move on to the next day's location to make sure it'll be ready first thing in the morning. We're constantly dealing with the past, present, and future all at once: open, maintain, clean up, close down, and then what's happening tomorrow?

Do you generally find that the location budgets cover what you need? Or do you often feel squeezed?

As I mentioned, I'm usually dealing with a \$1 or \$2 million budget on features. When you work episodic television, you're responsible for roughly $\$ 200,000$ per episode. I think the biggest challenges in location budgets are the constant unknowns. You never really know your incidental costs until the film is happening. Overages arise in aspects of security, police, fire, and permit costs. You must pad those line items to ensure you're covered. I find producers don't worry too much about individual line items. They're most concerned with the overall costs-what you've estimated for the whole project. So as long as you don't overspend your bottom line, you're in good shape. But, damn, things always change, especially schedules and weather. In those situations, you rob Peter to pay Paul. 
We just had to deal with a major schedule change on The Accountant. It was a very difficult negotiation to obtain permission to film in a high-end hotel lobby. They finally gave us a small window on a Monday morning from two to six. It's the only time they would allow us to film. I don't blame them. They're a business, and we're in the middle of their lobby. We were all set until Ben Affleck was invited to present the Oscar for Best Director at the Academy Awards ceremony, which of course coincided with the night shoot at the hotel. There was no way he would make it back to Atlanta in time. I call the hotel to explain. They don't care. It's a hotel. They're not in the movie business. They're not interested in working with me to find a new date. My producers are telling me to figure it out. Make it work. I do everything I can to negotiate a new schedule, but the hotel won't budge. I finally tell the producers we need help from someone more powerful than me. Sure enough, someone from the Warner Bros. top echelon makes a phone call to the hotel's owner. He agrees. We end up paying an additional $\$ 25,000$ to shoot the scene there. There was no way I could absorb that in my budget. It was too much. But the producers wanted it, and when the producers want it, they can always figure out a way to make it happen. They adjusted some other part of the budget and found the money.

\section{Why are you working in Atlanta so much?}

I'm not getting calls for L.A. Hollywood is in Atlanta now.

You're saying, "I'm so busy that I have to turn down jobs," whereas a lot of people in L.A. seem to be struggling with the opposite problem. Do you think it's because you've been willing to pick up and go?

I think so. I was willing to follow the work very early in the process. I don't think a lot of people shared that willingness for whatever reason-maybe they thought it was a temporary fad. But now they're realizing that it's not coming back anytime soon. More and more people are willing to pack up for work.

Why do you keep doing it?

I absolutely love Atlanta. It's a great city. And it's fun to learn a new place. I don't have any kids. My wife also travels for work. So, it fits our lifestyle.

There are no features in Los Angeles at all?

There are, but not many, and the budgets are small. It's hard to do anything in this town without money. People know the industry here. They know to ask for a certain amount of money when you're negotiating with them to use their house or 
business. Yet on low-budget features, you're trying to get as much as possible for as little as possible. I've done plenty of features on that level, but it was a long time ago. It was a great education for a twenty-eight-year-old. It's also much easier to rebound from all the running and gunning when you're young. It is too physically demanding for me. I would rather work on $\$ 25$ to $\$ 100$ million movies. You have more creative input and a little more leeway with time and money. Moreover, you don't end up burning bridges by constantly asking for favors; you don't "owe" anyone anything because you have the money to do the negotiations properly.

I know the California incentive has just changed. Maybe it will bring back some big-budget work. Maybe features actually written for L.A. will film in L.A. Will Ferrell and Kevin Hart's new comedy Get Hard (2015) takes place in Century City, South Central, Hollywood, and downtown Los Angeles. They filmed the whole thing in Louisiana.

\section{Do you miss Los Angeles?}

I do miss the city. I miss the weather, my friends, and my house. I would love to work here again on a more permanent basis. But this is the first time I've been back to L.A. in eight months. I have an empty house that just sits here. So, I feel like a gypsy. I've been doing this for four years already, and it does start to take a toll.

\section{Why has Georgia emerged as a production hub?}

They have weather that allows you to shoot year-round. You have a growing crew base. Right now there are more features than the city can staff, but they're working hard to catch up. They are establishing schools to help train crew. They are establishing postproduction facilities. They have excellent soundstages, and are building more. They have the equipment you need. You can make your entire film there. Today it's not much different than Los Angeles.

I remember when the area was relatively new to the industry. It was a lot cheaper. I was securing locations for half the price I would pay in Los Angeles because no one knew what to ask for. But that seemed to change overnight. Now everyone knows what we're willing to pay for a location. I find myself paying the same price to film in Atlanta homes that I would pay to film in Malibu homes. Of course, the incentive in Georgia helps offset those costs.

You say Atlanta is actually building capacity. But if the incentive disappears, does the capacity disappear, too?

There's so much momentum there. Pinewood Studios has built an outstanding facility. Disney and Marvel are there for a number of pictures in a row. If the 
incentive disappears, producers and studios might hesitate to return, but there's enough capacity being built that Atlanta will remain a hub. In fact, I work with at least ten service companies that have packed up from Hollywood and moved to Atlanta because they feel that it's a strategic business move. There's confidence that production is there to stay.

Can you talk more about the city's evolution? Staffing shortages exist, but the situation is improving. It's getting costlier to shoot there. What else do we need to know?

It was a logistically difficult place when we first started filming there. It didn't have an established film office until this year, 2015. Previously it was a woman who had a small desk with stacks and stacks of paper. You couldn't even see her behind them. She was responsible for all transportation projects around the city, not just film. It made permit approvals extremely difficult because it would take her forever to weed through her regular job before she even found your request. Now with the Atlanta Film Office, everything is so much more efficient. They'll help you navigate local bureaucracies. They'll help mediate problems with local businesses. They're happy to get involved. It's still a young organization with a learning curve, but already I can tell a difference in the city. They've been very receptive to feedback from location managers.

Do you think the value and status of location managers has risen as productions have become more mobile?

Absolutely. Studios are making huge features, and they're making them in a number of different hubs. It's a much more difficult process, both creatively and logistically. When I first started in the industry, location managers were on the outskirts of the production. But in the last ten years, I've noticed we have so many more responsibilities. We also garner much more respect thanks to organizations like the LMGA [Location Managers Guild of America]. We are looked to for creative and logistical answers. We are expected to have a certain expertise about how the production can do what it needs to get done in whatever location we're filming. It's a tough job.

Producers often talk about the competition to put the money on the screen. Locations are a big part of that. Yet we're in the era of computer-generated graphics. How has that affected your work?

Selma was the hardest project I've ever done. I was responsible for forty-six locations over a thirty-two-day shoot. We used CGI only when we needed to increase the number of extras; we sometimes had five hundred but needed ten thousand. 
We didn't use it for set extensions like we're doing with The Accountant. You definitely have to take CGI into consideration when you're selecting locations. Does this location give us the space to digitally insert the Chicago skyline into the background? In Atlanta, I've done Tikrit, Kuwait, London, and Tokyo. We've found it or created it but always with the help of CGI. Next week we're filming Lake Shore Drive in Atlanta. It's insane! You want me to find what? Why don't we just go to Lake Shore Drive?

Selma was a different set of problems. I had to consider the story's history; these events happened in actual locations. I also had to contend with a budget that didn't allow us to spend a lot of time outside of Atlanta. So, while most of the story takes place in Alabama, I was forced to find a lot of Selma, Alabama, in Atlanta, Georgia. Mark Friedberg, the production designer, was an amazing collaborator. We did so many side-by-side comparisons of the Selma locations and Atlanta locations. We had probably thirty different options for each location, then we would compare them until we found the best match. It was a great challenge. Because we were dealing with real locations, you didn't want someone in the audience who was part of that history to recognize the location as false: "Oh, that's not it!"

We've reached a point, I think, where certain places have emerged as reliable hubs. They have the soundstages and the crew and the incentive. There's no reason to go to Tikrit, I guess, when you can find it in Atlanta.

Can you identify the top five to ten hubs?

Atlanta. Louisiana. New Mexico. New York. London. Vancouver. Toronto. Australia. Cleveland has had some success lately; they're very film friendly. For Captain America: The Winter Soldier (2014) they shut down one of the city's major freeway arteries for weeks. They just opened their doors to the production and asked, "What can we do for you?"

Los Angeles is still the best place to shoot.

You just ticked off a map of global hubs but said L.A. is still number one. What do you mean?

You've got it all in Hollywood, and you can cheat to get different looks, depending on what you're shooting. It's hard to beat this city, but right now it just can't compete with the incentives that other places are offering. 